\title{
Oroesophageal Fish Bone Foreign Body
}

\author{
Heung Up Kim \\ Department of Internal Medicine, Jeju National University School of Medicine, Jeju, Korea
}

Fish bone foreign body (FFB) is the most frequent food-associated foreign body (FB) in adults, especially in Asia, versus meat in Western countries. The esophageal sphincter is the most common lodging site. Esophageal FB disease tends to occur more frequently in men than in women. The first diagnostic method is laryngoscopic examination. Because simple radiography of the neck has low sensitivity, if perforation or severe complications requiring surgery are expected, computed tomography should be used. The risk factors associated with poor prognosis are long time lapse after FB involvement, bone type, and longer $\mathrm{FB}(>3 \mathrm{~cm})$. Bleeding and perforation are more common in FFB disease than in other FB diseases. Esophageal FB disease requires urgent treatment within 24 hours. However, FFB disease needs emergent treatment, preferably within 2 hours, and definitely within 6 hours. Esophageal FFB disease usually occurs at the physiological stricture of the esophagus. The aortic arch eminence is the second physiological stricture. If the FB penetrates the esophageal wall, a life-threatening aortoesophageal fistula can develop. Therefore, it is better to consult a thoracic surgeon prior to endoscopic removal. Clin Endosc 2016;49:318-326

Key Words: Seafood; Bone and bones; Foreign bodies; Esophagus; Pharynx

\section{INTRODUCTION}

Aeroesophageal foreign body (FB) disease can be divided according to the involved organ: tracheobronchial tree, oropharynx, and esophageal or other gastrointestinal tract. In one study showing the distribution of aeroesophageal FB, $90 \%$ of patients had a retained $\mathrm{FB}$, while it passed in the other $10 \%$. Among the retained FB cases, it was found in the pharyngoesophagus in $86.2 \%$ of cases and in the tracheobronchial tree in $13.7 \%$ of cases. ${ }^{1}$ With rapid development of diagnostic and therapeutic gastrointestinal endoscopy, all pharyngeal and esophageal FB diseases, except for tracheobronchial, are considered gastroenterological. The fish bone is a very common cause of FB disease in areas in which the people frequently

Received: June 27, 2016 Revised: July 10, 2016

Accepted: July 12, 2016

Correspondence: Heung Up Kim

Department of Internal Medicine, Jeju National University Hospital, Jeju National University School of Medicine, 15 Aran 13-gil, Jeju 63241, Korea

Tel: +82-64-717-1129, Fax: +82-64-717-1131, E-mail: kimhup@jejunu.ac.kr

(c) This is an Open Access article distributed under the terms of the Creative Commons Attribution Non-Commercial License (http://creativecommons.org/ licenses/by-nc/3.0) which permits unrestricted non-commercial use, distribution, and reproduction in any medium, provided the original work is properly cited. eat fish. The esophageal fish bone foreign body (FFB) diseases have a wide spectrum of clinical manifestations from minor disease that can resolve spontaneously to severe fatal diseases. This article addresses the esophageal FFB diseases including pharyngeal FB because their symptom manifestations are similar from the patient perspective.

\section{FISH BONE FOREIGN BODY IN THE ESOPHAGUS AND PHARYNX}

\section{General aspect}

The major causes of FB disease differ between children and adults. FB diseases due to nonfood objects are more common in children than in adults, especially those 6 months to 6 years of age. ${ }^{2-6}$ Coins are most common in children. ${ }^{7}$ Adult true FB diseases are common in individuals who are elderly, have psychiatric conditions, have developmental disabilities, are inebriated, or are prisoners seeking a secondary gain. ${ }^{5,8-10}$ The main causes of foodborne FB diseases also vary among geographic regions and cultures. The most common esophageal FB diseases in adults in the Western world are due to impacted meat or other food, ${ }^{5}$ with an estimated annual incidence of 
13/100,000 people. ${ }^{11}$ However, in the Asian culture or coastal areas, fish bone is the most common cause. ${ }^{12-14}$ Approximately $80 \%$ to $90 \%$ of ingested FBs are passed spontaneously without complications, ${ }^{15-18}$ while $10 \%$ to $20 \%$ of FBs in the alimentary tract require endoscopic removal and approximately $1 \%$ require surgical intervention. ${ }^{15-18}$ However, intentionally ingested FBs much more commonly require endoscopic treatment (63\% to $76 \%$ ) and surgery (12\% to $16 \%) .{ }^{19,20}$ Mortality is not uncommon in FB diseases. In the 1970s, approximately 1,500 people in the United States died annually of FB diseases. ${ }^{21}$ Therefore, clinicians should remember that FB diseases can be serious or even fatal.

\section{Epidemiology}

Contrary to Western countries where the food bolus impaction is more common, ${ }^{5} \mathrm{FFB}$ are most common in Asia. ${ }^{12-14}$ In South China, fish bone ingestion is most common (60\%) among the FB diseases and becomes more prevalent with time..$^{22}$ In Korea, FFB is most common ( $46 \%$ to $72.3 \%$ ) in upper gastrointestinal FB disease. ${ }^{23-26}$ Sex distributions varied among centers. Many institutes have shown a male predominance. ${ }^{2-4,23-25,27,28}$ However, other institutes have shown a female predominance. ${ }^{26,29}$ Mean ages differed by study design; however, in two studies of adult FFB, the mean female age was somewhat higher than the mean male age. . $326^{26}$

There are no well-controlled epidemiologic data of the incidence of FFB diseases in Korea. The results reported to date differed among institutes and the main treating department. Two studies of treatment in the ear-nose-throat department (ENT) setting are available. In the consortium of Seoul National University Hospital, Seoul National University Boramae Medical Center, and Seoul National University Bundang Hospital (midwestern coastal region in Korea), 270 patients were diagnosed with FFB in the oropharynx over 61 months. ${ }^{30}$ The other study reported treatment in the ENT department of Gyeongsang National University Hospital (southern coastal region in Korea) of a total of 198 cases of FFB disease over 21 months, of which approximately $37.9 \%$ of patients were $<20$ years of age. ${ }^{29}$

Several epidemiologic data have been reported in the gastroenterology setting. In Gyeongsang National University Hospital, 188 cases of esophageal FFB disease were diagnosed over 71 months (January 1998 to November 2003) $;^{24}$ in Asan Medical Center (midwestern coastal region in Korea), 196 cases of esophageal FFB disease were diagnosed including 13 cases of esophageal perforation over 91 months (January 2000 to July 2008); ${ }^{31}$ in Jeju National University Hospital (southern island in Korea), 77 cases of pharyngoesophageal FFB diseases were diagnosed over 89 months (March 2004 to March 2011); ${ }^{26}$ and in Dankook University Hospital (central inland in
Korea), 113 cases of esophageal FFB diseases including three child patients were diagnosed over 168 months (January 2001 to December 2014). ${ }^{23}$

\section{Lodging site}

One study reported that in the ENT setting, oropharyngeal FFBs are more common in young patients, while esophageal FFB is primarily observed in patients $>40$ years of age. ${ }^{29}$ They suspected the reason for the rapid increase in FFB in the esophagus in people $>40$ years is related to deterioration of the swallowing movement and esophageal physiological characteristics that develop with age. ${ }^{29,32}$ However, in the gastroenterology setting, esophageal FFB is more common than oropharyngeal FFB. ${ }^{23,25,26}$

Frequent lodging sites in the oropharynx are the tonsils, tongue base, valleculae, and pyriform recesses, the tonsils being the most common site. ${ }^{29,30,32,33}$ Some authors suggested inspecting the tonsils first prior to evaluating another pharyngeal regions. ${ }^{34}$ Major complications of FB such as impaction, perforation, or obstruction usually occur in areas of gastrointestinal angulation or narrowing. ${ }^{35}$ It is well known that the esophagus has three areas of physiological narrowing: the upper esophageal sphincter, eminence of the aortic arch or the left main bronchus, and the lower esophageal sphincter. In addition, an anatomical pathology, such as stenosis, will create another site. The upper esophageal sphincter is the most common lodging site of $\mathrm{FFB}^{7,12,23,24,26,36}$ It is very important to know, at least in cases of sharp-pointed FB objects, that the aortic eminence is a physiological stricture. A sharp FFB lodged within the second physiological stricture that penetrates the esophageal wall can cause a fatal aortoesophageal fistula (AEF).

FFB shape also influences the lodging site. In one study, flat or polygonal FFBs tended to involve the esophagus, whereas linear bones more commonly became lodged in the phar$\mathrm{ynx}^{26}$

\section{Causative fish species as origin of FFB}

Many patients with FFB could not recall what kind of fish they ate. Causative fishes differ among regions and cultures. In Jeju, the most common FFB fish is the damselfish (Chromis notata), followed by armorclad rockfish and houttuyn ${ }^{26}$ Contrary to Jeju, the three most common species were groaker, turbot, and rockfish in Jinju province. ${ }^{29}$ In the Seoul-Gyeonggi region, mackerel, yellow corbina, and cutlass fish were common, although incidences varied among institutes. ${ }^{30}$

Fish recipes may influence FFB disease. In one study, fish stew caused the highest number of cases of esophageal FB disease, followed by baked fish, steamed fish, and raw fish. ${ }^{29}$ Another study showed soup recipes, including stew, were 

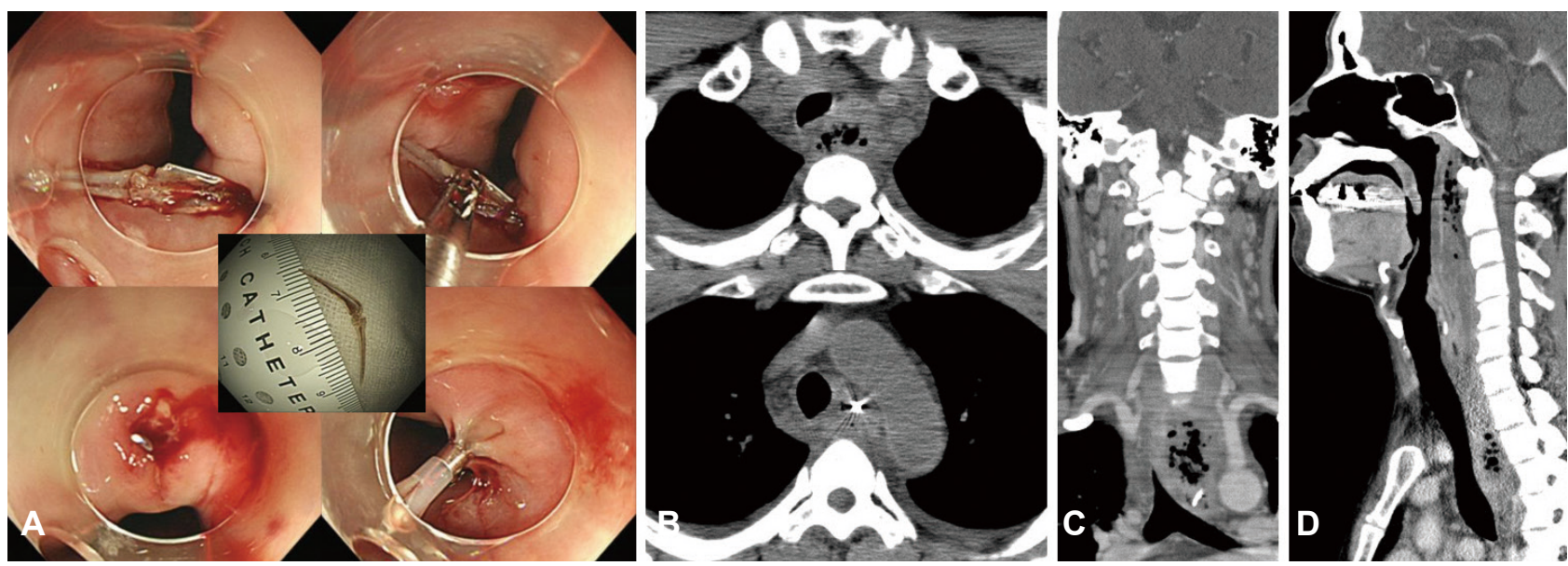

Fig. 1. Complicated case of esophageal fish bone foreign body (FFB) of a 43-year-old man who had alcoholic liver cirrhosis and chronic pancreatitis and had complained of back pain since 3 days before. (A) Endoscopic photography shows a typical damselfish ("Jari" in Korean) FFB near the aortic arch eminence. There was no evidence of an aortic arch injury on the first computed tomography (CT). During endoscopy, the FFB impacting one side of the esophageal wall was removed using foreign body forceps and the penetrated hole was sutured using a hemoclip. Approximately a $2.5-\mathrm{cm}$ length of typical "anal fin spine-pterygiophore complex" FFB was removed successfully. On the second hospital day, fever and dyspnea were aggravated. On the follow-up CT, pneumomediastinitis with abscess formation was seen (B, cross-section; C, coronal section; D, sagittal section). Note that free air and inflammatory material extended up to the retronasopharyngeal space. The patient transferred to the surgical ward and underwent surgery on hospital day 3 . The postoperative course was uneventful and the patient was discharged on hospital day 30.

the most common culprits. ${ }^{26}$ However, this can depend on fish type. ${ }^{26}$ In Jeju province, the most common FFB disease is caused by damselfish bones, especially by the anal fin spine-pterygiophore complex, which causes more serious complications due to its peculiar shape (Fig. 1). ${ }^{26}$ Esophageal linear slender FFBs can be passed to stomach. However the sharp pointed linear FFB could be remained in the esophagus because it can penetrate the mucosa and anchored in the esophagus.

\section{Symptoms}

The diagnosis of FFB is based on the patient's diet history and symptoms. A physical examination should evaluate the patient's general condition and assess signs of any complications. ${ }^{18}$ The symptoms of esophageal FB diseases are FB sensation, sore throat, dysphagia, odynophagia, retrosternal pain, retching, and vomiting. ${ }^{16,17,37,38} \mathrm{FB}$ sensation and localized pain could be the main complaints in the early period of FFB disease. Later, localized inflammatory or systemic symptoms by the progression of complications may become evident. Patients can generally identify the ingestion and localize the discomfort. However, the area of discomfort often does not correlate with the site of impaction. ${ }^{39}$ Patients could identify the correct location if the FB is lodged in the upper esophagus or above. However, below this region, the symptoms became vague, making localization of the impact site difficult. Severe and systemic symptoms such as swelling and crepitus on the neck, hematemesis, dysphagia, dyspnea, fever, and chest and back pain can be reported after complications develop.
Esophageal abrasions secondary to ingested FB can often mimic impaction. FB sensations can persist for several hours even after the FB has passed the esophagus or has been removed endoscopically. ${ }^{18}$ It is very embarrassing for patients and physicians when no FB is found endoscopically for patients who complain of FB sensations. In such cases, computed tomography (CT) can be a good alternative. If there is no detected $\mathrm{FB}$ on the $\mathrm{CT}$ of the patient who complains of an FB sensation, the doctor can state "no FB" with high confidence because CT has a high negative predictive value (up to $97 \%)^{40}$

\section{Radiologic evaluation}

Radiographic study of the neck, chest, and abdomen is needed to assess the presence, location, size, configuration, and number of ingested objects. It also helps to detect FB-induced complications. ${ }^{18,41,42}$ Contrary to nonfood objects and large animal bones that can mostly be identified on radiography, fish bones are difficult to be identified on radiography. ${ }^{18}$ The detection rate of plain radiography is dependent on bony calcification or fish type. ${ }^{43}$ Although plain radiography is recommended as the initial screening method, its sensitivity for detecting FFB is only $32 \%$ and false-negative rate is reportedly as high as $47 \% .^{27}$ Biplane radiography helps detect FB that is not detectable on plain radiography (Fig. 2). ${ }^{18} \mathrm{Im}$ aging both the anteroposterior and lateral views increases the detection rates of $\mathrm{FB}$ and free mediastinal or peritoneal air. ${ }^{42}$ Because the anteroposterior view of the neck rarely detects $\mathrm{FFB}$, the lateral view is better for detecting oropharyngeal and upper esophageal FFB (Fig. 3A, B). 

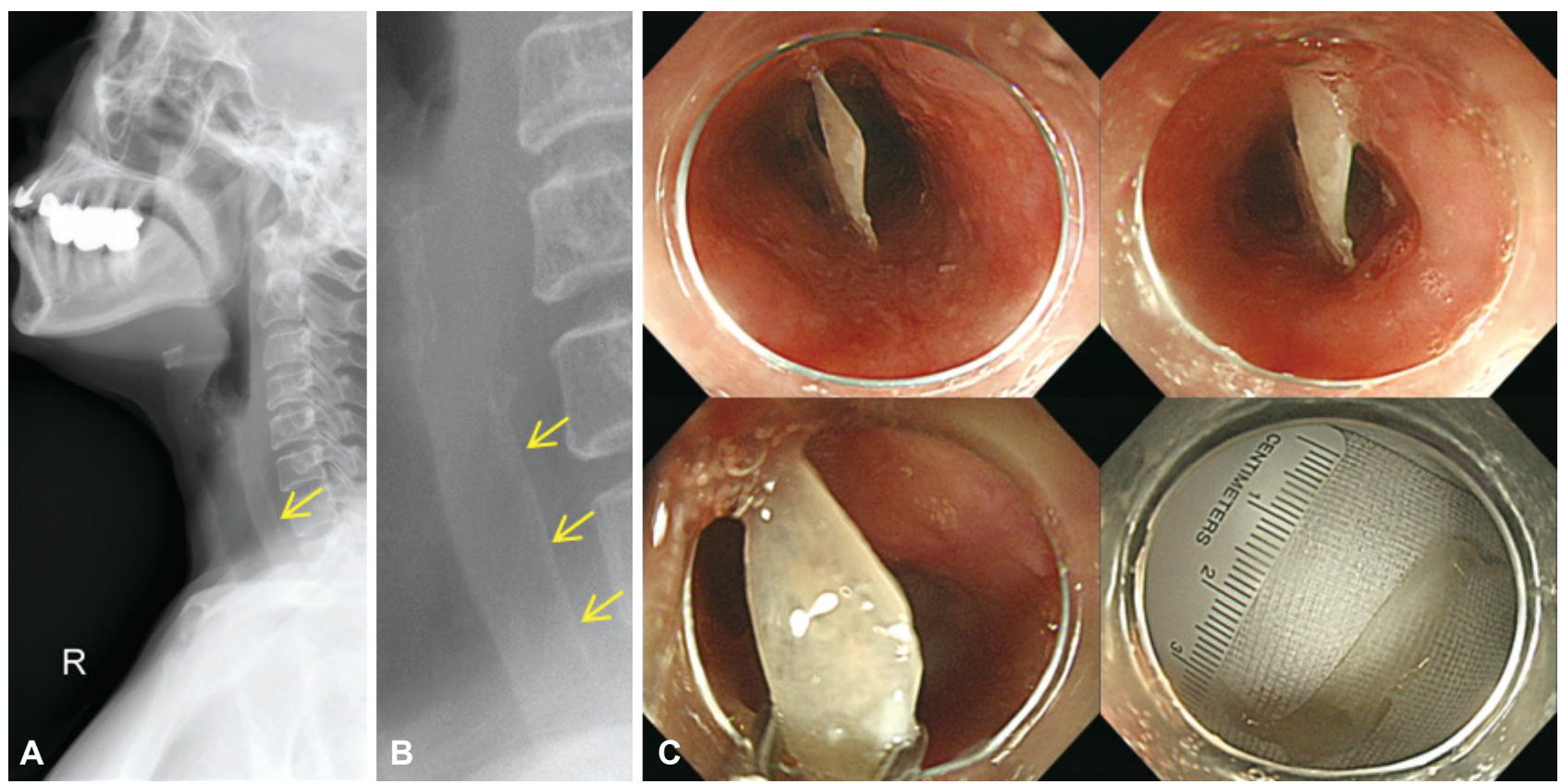

Fig. 2. A typical case of upper esophageal fish bone foreign body (FFB) disease in a 62-year-old woman complaining odynophagia after eating a fish (Lateolabrax japonicus) 1 day before. (A) On the neck lateral X-ray (NLX) and (B) its magnified view, about $3 \mathrm{~cm}$ of linear opacity was seen. (C) The FFB was removed using cap-fitted endoscopy. In cases of upper esophageal FFB above the thoracic inlet, a simple NLX is a useful single modality to diagnose the FFB disease prior to do endoscopic examination without need to check computed tomography. Arrows denote FFB.

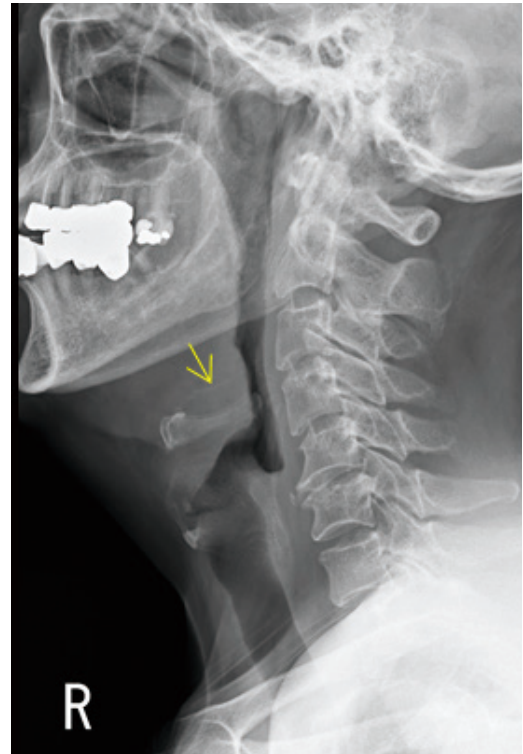

A
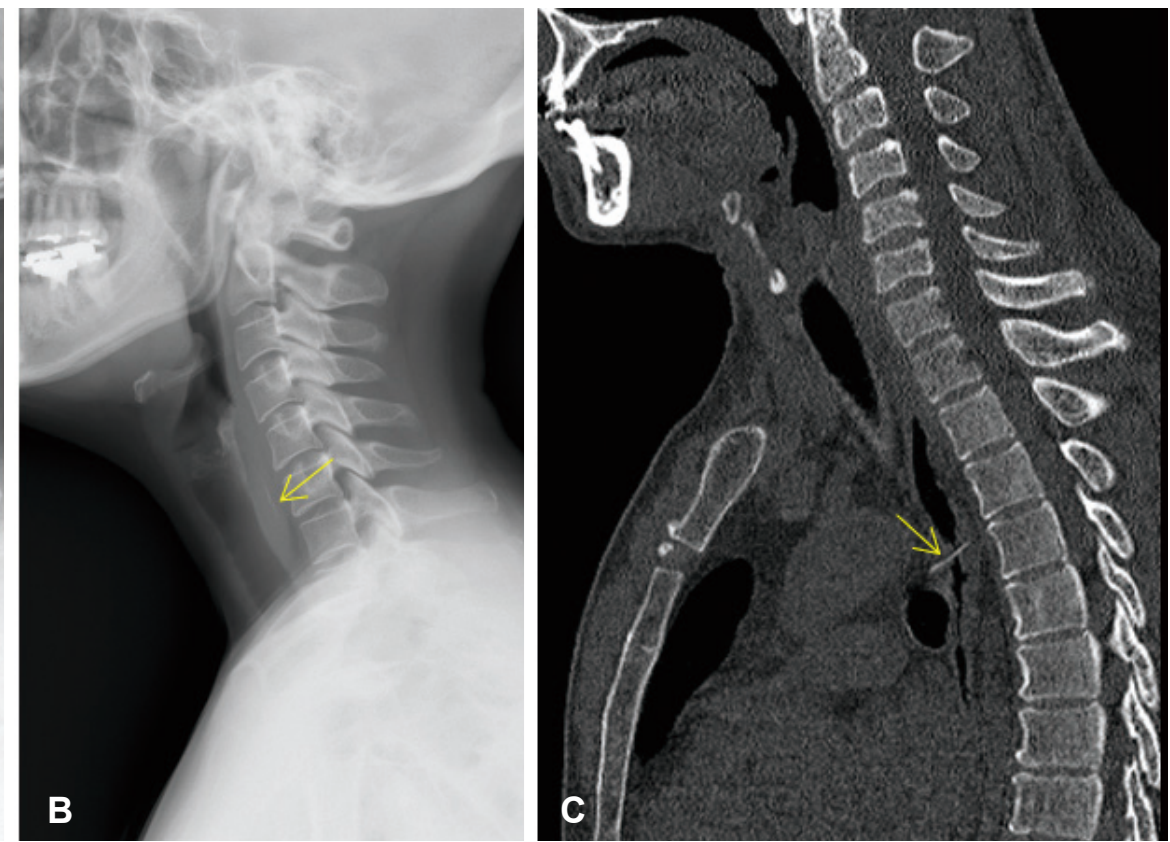

Fig. 3. Neck lateral X-ray (NLX) and computed tomography (CT) to identify fish bone foreign bodies (FFBs). (A) Hypopharyngeal FFB. (B) Cervical esophageal FFB. (C) Thoracic esophageal FFB. The hypopharyngeal and cervical esophageal FFB are well detected on the NLX. However, below the thoracic inlet, only CT can detect the FFBs. Arrows denote FFBs.

The FB lodged below the thoracic inlet could not be detected with plain radiography, even in the lateral view. CT is superior to plain radiography for localizing and identifying $\mathrm{FB}$ and is highly reliable for localizing $\mathrm{FB}$ in the esophagus (Fig. 3C). ${ }^{46}$ CT has high sensitivity ( $90 \%$ to $100 \%)$ and specificity $(93.7 \%$ to $100 \%){ }^{47-50} \mathrm{CT}$ sensitivity may increase with three-dimensional reconstruction, i.e., coronal or sagittal views. ${ }^{51}$ Positive and negative prospective values of CT are $75 \%$ and $97 \%$, respectively. ${ }^{40} \mathrm{CT}$ is a very useful method in cases of imbedded FB that require focused diagnosis and treatment as well 

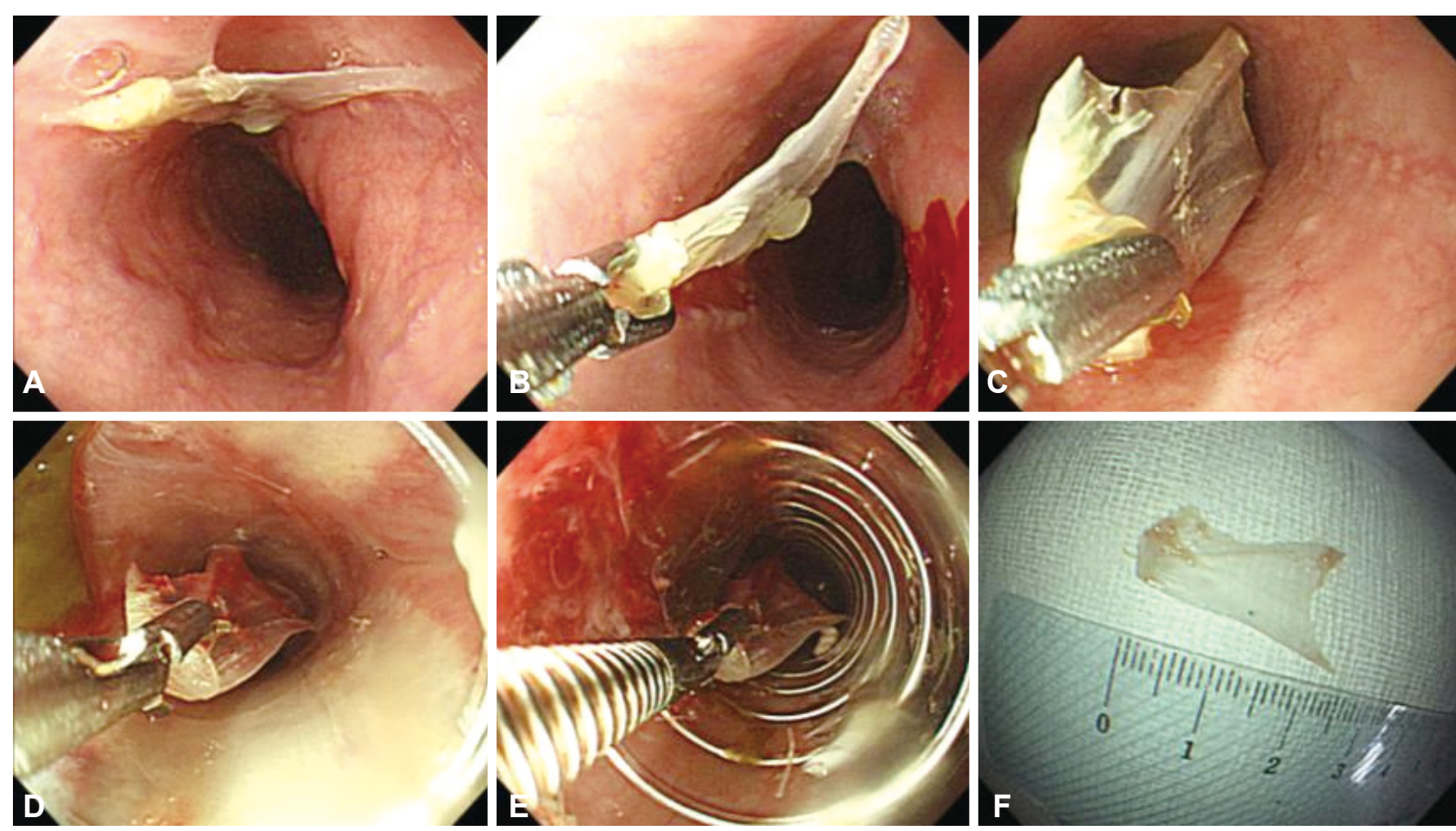

Fig. 4. (A-F) Serial endoscopic photos of removal of the esophageal flat fish bone foreign body (FFB) using an overtube. Many esophageal FFB are flat, large, and have a sharp polygonal edge. For this reason, esophageal laceration can be evoked during FFB retrieval, especially upper esophageal sphincter. Using an overtube not only protects the upper esophageal mucosa from laceration but also helps protect the airway from aspiration.

as in cases of passed FB with remaining FB sensation. $\mathrm{CT}$ is an essential diagnostic modality for detecting and predicting FB-related current or impending complications.

Contrast esophagography is not recommended as an initial diagnostic modality because of the related high risk of aspiration and interference with the subsequent endoscopic visual-

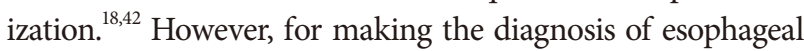
perforation, esophagography remains the standard. The use of a water-soluble contrast agent is the first choice because it can be absorbed rapidly despite a low detection rate (50\% of cervical and $75 \%$ to $80 \%$ of thoracic perforation cases), while the barium contrast exam is used as a rescue method. ${ }^{52}$ The overall false-negative rate of esophagography for detecting perforations is $10 \%$. However, clinicians should remember that aspiration of the hypertonic water-soluble contrast solution leads to pulmonary edema. ${ }^{38}$

\section{Initial evaluation and timing for treatment}

Initial management includes assessing the airway and respiratory status to identify patients who are at high risk of aspiration. ${ }^{42}$ Although $>80 \%$ of FB may pass without intervention, ${ }^{15}$ esophageal FB should be treated more urgently than gastric FB since it is more likely to become obstructed and aspirated since the esophagus features a narrow lumen and thin wall that is vulnerable to pressure or perforating force, is located at the center of major organ, and is more easily accessible with endoscopy than the stomach. Many authors have reported that esophageal FB and food impactions should be removed within 24 hours because treatment delay decreases the possibility of successful removal and increases the risk of complications. ${ }^{2,53}$ FFB disease has a higher risk of severe complications if the treatment is delayed beyond 24 hours $^{54}$ and a high frequency of bleeding compared to other FB diseases. ${ }^{28}$ Some authors recently recommended a more aggressive treatment for patients with high-risk status, including FB inducing complete esophageal obstruction and the ingestion of a sharp object or battery into the esophagus. ${ }^{18}$ They recommended emergent (preferably within 2 hours, but within 6 hours at the most) therapeutic esophagogastroduodenoscopy (EGD) for patients with high-risk esophageal $\mathrm{FB}$ as well as urgent (within 24 hours) EGD for other esophageal FB. ${ }^{18}$ Most FFB are sharp objects, so FFB should be treated emergently.

\section{Treatment modality}

The initial assessment of the patient complaining of an FB sensation in the neck consists of an oral cavity examination with a tongue depressor and a pen light. The next step is direct laryngoscopic examination, followed by flexible or rigid endoscopy. ${ }^{42}$ Although flexible endoscopy of ENT has a lower risk of perforation and a high success rate, ${ }^{18}$ rigid endoscopy 

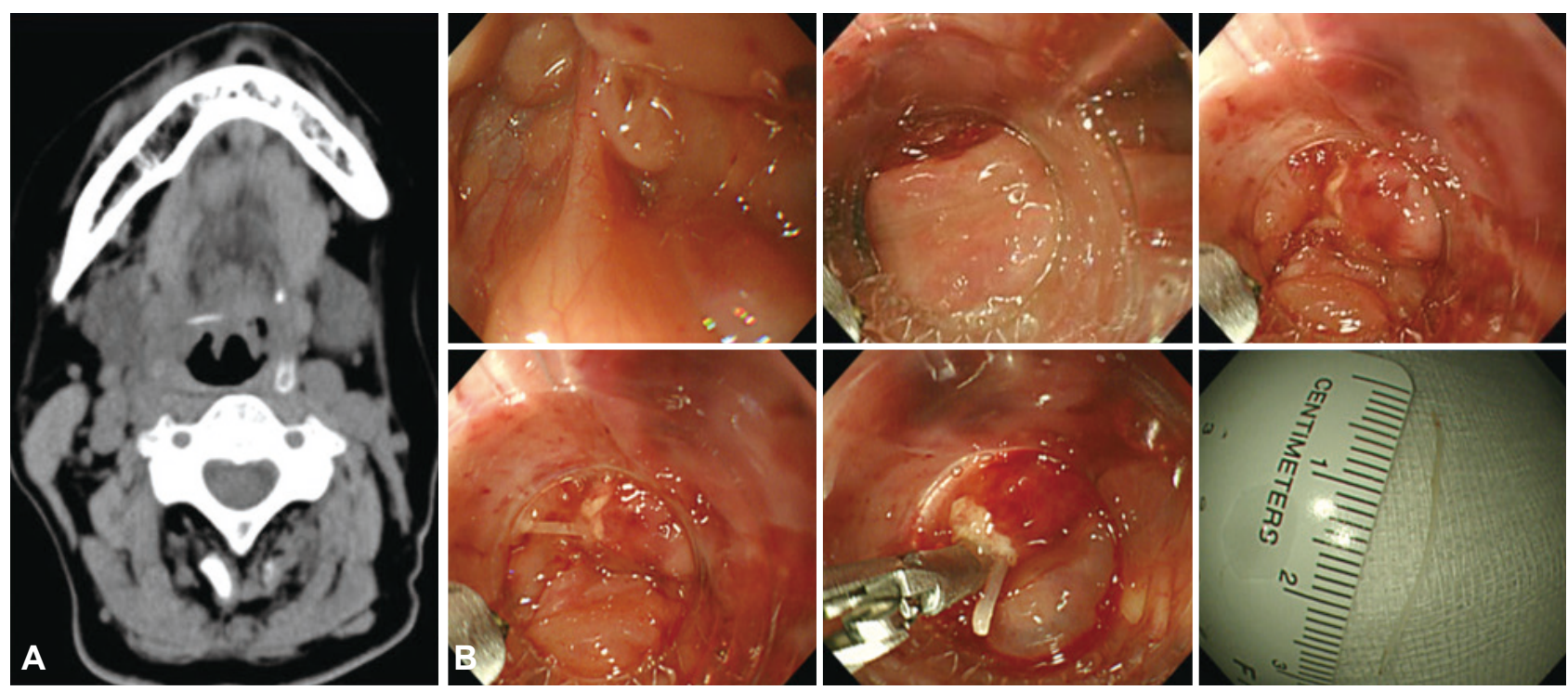

Fig. 5. Usefulness of cap-fitted endoscopy in the collapsed pharyngeal space. A linear fish bone foreign body (FFB) is totally imbedded in the right vallecula on computed tomography (A). Serial photos to find, expose, and remove the imbedded FFB (B). The naked endoscopic tip cannot approach and visualized the collapsed space. The cap-fitted endoscopy is useful not only visualize the collapsed mucosa but also detect and expose the imbedded FFB by sweeping mucosa with the edge of the cap. Cap also makes the sufficient space to operate the forcep to remove the FFB in the collapsed space.

has some advantages for FB impacted in the upper esophageal sphincter or hypopharyngeal region. ${ }^{55}$

Since EGD is a widespread and rapidly developed therapeutic technique, it has recently become the first therapeutic modality for the pharyngoesophageal FFB disease in Korea. Because CT is an expensive diagnostic modality, simple radiology only could be used prior to EGD in many institutions since it allows the examination of both the pharynx and upper esophagus in patients complaining of only a "neck" FB sensation. Therefore, the endoscopist should meticulously evaluate the oropharyngeal mucosa prior to entering the upper esophageal sphincter.

In cases of non-sealed perforation, abscess formation, complete object imbedding beyond the lumen, uncontrolled bleeding and infection, and adjacent organ injury, surgical treatment may be indicated. Minimal invasive surgeries were recently introduced. ${ }^{56}$

An FFB is a sharp FB that can penetrate the mucosa and wall of the digestive tract. Although the esophageal wall is totally penetrated by a small linear FFB, significant air and liquid leakage rarely occur in the early phase because the penetrated hole may be sealed by the FFB itself. In this case, short-term antibiotics can be used prophylactically. However, in cases of gross perforation, laceration, and pus discharge, it should be managed as mediastinitis. In one study, the FFB tended to become impacted in a transverse position rather than a parallel or oblique position in the pharynx and esophagus. This tendency enables the FFB to more easily penetrate the esophageal wall, particularly linear and sharp objects. As such, if the FFB has two pointed ends, it can penetrate both esophageal walls, which would decrease the luminal stretching power and create an FB sensation in the early phase that may delay hospitalization.

\section{Protect and retrieval devices}

Protective devices are needed to avoid mucosal damage and aspiration during endoscopic FB removal, and endotracheal intubation should be considered in cases with a high risk of aspiration. ${ }^{18}$ An overtube is useful to protect mucosal damage during FB retrieval and create additional airway protection (Fig. 4). ${ }^{37,38,57} \mathrm{~A}$ transparent cap is also useful for protecting the mucosa during FB retrieval and providing a clear visual field within the collapsed lumen during endoscopy (Fig. 2). It is a safe and effective method for removing upper esophageal FB and shortening operative time. ${ }^{58}$ The transparent cap is also useful for pharyngeal FB (Fig. 5)..$^{59}$ A rubber hood can be used to protect the esophageal mucosa during retrieval of sharp objects. ${ }^{18}$

The choice of retrieval device is determined by the FB and endoscopy characteristics as well as the endoscopist's preference. Appropriated retrieval devices to remove sharp-pointed objects include grasping forceps, polypectomy snare, basket, retrieval net, transparent cap, and latex rubber hood..$^{18}$ Rat tooth and alligator forceps are the main grasping forceps used to retrieve the FFB. The difference of these two forceps is the grasping surface: The former can grasp FB with its tooth-like tip (Fig. 4B), whereas the latter grasps it using its entire jaw. Conventional standard biopsy forceps may not be recom- 
mended except for small linear FFB due to its small opening width, which decreases the success rate. ${ }^{16}$ In cases of flat FFB, the polypectomy snare, basket, and retrieval net also can be used.

\section{Complications}

Serious complications are more frequent in adults than in children. Aspiration, asphyxia, and obstruction would be most serious complications in cases of food bolus impaction. However, in FFB disease, the primary insults of FFB inducing complications are initiated by penetration/perforation and laceration of the pharyngoesophageal wall. Esophageal perforations due to $\mathrm{FB}$ ingestion account for $1 \%$ to $4 \%$ of the total reported cases. ${ }^{60}$ However, in FFB, esophageal penetration or perforation reportedly occur in $>50 \%$ of cases. ${ }^{26}$ After the insult, infection and adjacent organ damage can develop.

In one study, esophageal perforation was present in 18 of 196 patients with esophageal FB. Among the 18 cases of perforation, 13 were FFB diseases. Of the 13 cases of perforated FFB disease, six underwent surgical operation; primary closure and drainage, esophageal resection, and colon interposition, open thoracotomy after neck incision and drainage (I\&D), empyectomy, thoracoscopic drainage, and $I \& D{ }^{31}$

The risk of complications was increased with a longer duration of impaction ( $>24$ hours), ${ }^{54}$ bone type ${ }^{26}$ and longer bone length $(>3 \mathrm{~cm}){ }^{61}$ FFB more frequently features bleeding than other kinds of $\mathrm{FB}^{28}$ In pharyngeal FFB, deep neck infection, neck abscess, epidural abscess, ${ }^{62}$ and retropharyngeal hematoma $^{63}$ are the main complications, and the FFB can migrate through the soft tissue of the neck to the skin. ${ }^{64}$ If the FFB erodes the esophageal mucosa, esophageal dissection and intramural hematoma ${ }^{65,66}$ or abscess formation could be possible. ${ }^{67}$ When the FFB penetrates the entire esophageal wall to the airway, tracheoesophageal fistula, ${ }^{68,69}$ recurrent pneumonia, ${ }^{70}$ lung abscess, ${ }^{71}$ empyema, ${ }^{72}$ or pneumothorax can develops. Mediastinitis ${ }^{73}$ and abscess formation is the most common complication when the FFB penetrates the entire esophageal wall (Fig. 1). If the FFB advances to the heart, pericarditis, ${ }^{74}$ cardiac tamponade, infectious endocarditis, ${ }^{75}$ and systemic air embolism ${ }^{76}$ may occur.

The major concern is penetration of a major vascular structure, especially the aorta and aortic arch. It is well known that the aortic arch eminence is the second physiological stricture of the esophagus. If a sharp FFB becomes lodged and penetrates the aortic arch eminence, a pseudoaneurysm ${ }^{77}$ or $\mathrm{AEF}^{78,79}$ can develop. AEF is the most serious complication of FFB disease in the esophagus. If an endoscopist accidentally detects an FFB impacting the aortic eminence, it is better to stop the endoscopic procedure immediately and switch to CT. Once the FFB has been observed to have caused an aortic injury on CT, the physician should consult thoracic surgery prior to starting endoscopy.

\section{Difficult case}

Once an FB enters the stomach, it can pass uneventfully, even if sharp. ${ }^{5,15,19}$ In the case of food bolus impaction, the push technique is the primary treatment method. ${ }^{11} \mathrm{~A}$ food bolus is a blunt material that does not injure the mucosa and can be digested by enzymes in the stomach and small bowel. An endoscopist may push the FFB into the stomach to reposition and grasp the FFB more safely. Although the majority of sharp objects in the stomach will pass without incident, the risk of complications is as high as $35 \%{ }^{37,42}$ Therefore, it is recommended that clinicians not push the FFB into the stomach and retrieve a sharp FFB from the stomach or proximal duodenum endoscopically whenever possible. If the FFB cannot be retrieved endoscopically, inpatient treatment and close clinical observation may be needed. ${ }^{18}$ Daily radiographs are recommended for sharp objects such as FFB. Surgery must be considered considering the possibility of perforation or the failure to progress within 3 days after ingestion. ${ }^{18} \mathrm{~A}$ bowel-perforating FFB can cause an insidious course of actinomycosis. $^{80,81}$

As time lapses after a whole FFB penetrates the pharyngeal or esophageal wall, the FFB may migrate deeper and the overlying epithelium heal. In that case, there will be lack of clues on endoscopy and barium esophagography. ${ }^{61}$ Finger sweeping could be helpful for an oropharyngeally imbedded $\mathrm{FFB}^{27}$ However, CT is the only technique that is able to detect FFB in the esophagus below the thoracic inlet. If FFB is totally imbedded through a pharyngoesophageal wall, a case-by-case approach depending on the FB size and patient's clinical condition is suggested. Most completely imbedded FBs require surgical treatment. However, because the FFB itself is a kind of bony fragment, a small and slender FFB might be absorbed gradually over time. ${ }^{73,82}$

\section{CONCLUSIONS}

The FFB is the most frequent esophageal FB in adults in Asia. The upper esophageal sphincter is most frequently involved. An FFB should be removed as soon as possible $(\leq 24$ hours). A long time lapse is associated with a high risk of complications. Because the sensitivity of simple radiography is low, CT is considered if complications are suspected. To avoid aspiration and mucosal laceration, the use of an overtube and a transparent hood is recommended during EGD. ${ }^{34} \mathrm{FFB}$ disease can cause severe fatal conditions, especially AEF. In the case of suspected AEF, the clinician should consult the thorac- 
ic surgeon prior to removing the FB by EGD. In failed cases of FB removal, patients should be managed with a case-by-case approach depending on the clinical condition.

\section{Conflicts of Interest}

The author has no financial conflicts of interest.

\section{REFERENCES}

1. Kamath P, Bhojwani KM, Prasannaraj T, Abhijith K. Foreign bodies in the aerodigestive tract: a clinical study of cases in the coastal belt of South India. Am J Otolaryngol 2006;27:373-377.

2. Park JH, Park CH, Park JH, et al. Review of 209 cases of foreign bodies in the upper gastrointestinal tract and clinical factors for successful endoscopic removal. Korean J Gastroenterol 2004;43:226-233.

3. Moon JS, Kim YH, Song TJ, Ryu HS, Hyun JH. The foreign bodies in the upper gastrointestinal tract diagnosed by endoscopy. Korean J Gastrointest Endosc 1990;10:305-315.

4. Lee MS, Ra DJ, Kim JH, Cho SW, Shim CS. A review of the endoscopic extraction in 52 cases of the upper gastrointestinal foreign bodies. Korean J Gastrointest Endosc 1990;10:47-52.

5. Webb WA. Management of foreign bodies of the upper gastrointestinal tract: update. Gastrointest Endosc 1995;41:39-51.

6. Hachimi-Idrissi S, Corne L, Vandenplas Y. Management of ingested foreign bodies in childhood: our experience and review of the literature. Eur J Emerg Med 1998;5:319-323.

7. Park SM, Chung MS, Choi JY, et al. Gastrointestinal foreign bodies: review of 118 cases. Korean J Gastroenterol 1999;33:464-472.

8. Blaho KE, Merigian KS, Winbery SL, Park LJ, Cockrell M. Foreign body ingestions in the Emergency Department: case reports and review of treatment. J Emerg Med 1998;16:21-26.

9. Kamal I, Thompson J, Paquette DM. The hazards of vinyl glove ingestion in the mentally retarded patient with pica: new implications for surgical management. Can J Surg 1999;42:201-204.

10. Abdullah BJ, Teong LK, Mahadevan J, Jalaludin A. Dental prosthesis ingested and impacted in the esophagus and orolaryngopharynx. J Otolaryngol 1998;27:190-194.

11. Longstreth GF, Longstreth KJ, Yao JF. Esophageal food impaction: epidemiology and therapy. A retrospective, observational study. Gastrointest Endosc 2001;53:193-198.

12. Nandi P, Ong GB. Foreign body in the oesophagus: review of 2394 cases. Br J Surg 1978;65:5-9.

13. Ono J. Foreign bodies in air and food passages in the Japanese. Arch Otolaryngol 1965;81:416-420.

14. Lai AT, Chow TL, Lee DT, Kwok SP. Risk factors predicting the development of complications after foreign body ingestion. Br J Surg 2003;90:1531-1535.

15. Carp L. Foreign bodies in the intestine. Ann Surg 1927;85:575-591.

16. Dray X, Cattan P. Foreign bodies and caustic lesions. Best Pract Res Clin Gastroenterol 2013;27:679-689.

17. Pfau PR. Removal and management of esophageal foreign bodies. Tech Gastrointest Endosc 2014;16:32-39.

18. Birk M, Bauerfeind P, Deprez PH, et al. Removal of foreign bodies in the upper gastrointestinal tract in adults: European Society of Gastrointestinal Endoscopy (ESGE) Clinical Guideline. Endoscopy 2016;48:489496.

19. Palta R, Sahota A, Bemarki A, Salama P, Simpson N, Laine L. Foreign-body ingestion: characteristics and outcomes in a lower socioeconomic population with predominantly intentional ingestion. Gastrointest Endosc 2009;69(3 Pt 1):426-433.

20. Weiland ST, Schurr MJ. Conservative management of ingested foreign bodies. J Gastrointest Surg 2002;6:496-500.

21. Schwartz GF, Polsky HS. Ingested foreign bodies of the gastrointestinal tract. Am Surg 1976;42:236-238.

22. Zhang S, Cui Y, Gong X, Gu F, Chen M, Zhong B. Endoscopic management of foreign bodies in the upper gastrointestinal tract in South China: a retrospective study of 561 cases. Dig Dis Sci 2010;55:1305-1312.

23. Park SJ, Jeon SM, Shin HD, et al. Risk factors for severe complications in patients with esophageal foreign bodies. Korean J Med 2015;89:537-547.

24. Kim HJ, Lee OJ, Min HJ, et al. Endoscopic treatment of esophageal foreign bodies in adult: management of 257 cases. Korean J Gastrointest Endosc 2004;29:51-57.

25. Park YK, Kim KO, Yang JH, Lee SH, Jang BI. Factors associated with development of complications after endoscopic foreign body removal. Saudi J Gastroenterol 2013;19:230-234.

26. Kim HU, Song HJ. Clinical characteristics of an esophageal fish bone foreign body from Chromis notata. J Korean Med Sci 2012;27:12081214.

27. Kim HU, Song HJ, Choi EK, Cho YK, Song BC. A case of a pharyngeal impacted fish bone foreign body detected by finger palpation. Korean J Gastrointest Endosc 2011;42:228-231.

28. Lee KS, Lee SH, Suh IS, Kim EH, Choi YW, Lee YU. Review of 78 cases foreign body in the upper gastrointestinal tract. Korean J Gastroenterol 1998;31:598-604.

29. Kim JP, Kwon OJ, Shim HS, Kim RB, Kim JH, Woo SH. Analysis of clinical feature and management of fish bone ingestion of upper gastrointestinal tract. Clin Exp Otorhinolaryngol 2015;8:261-267.

30. Chung H, Kwak YH, Kim DK, Jung JY, Lee JH, Kim HB. Usefulness of plain radiographs for management of suspected fishbone impaction in digestive tract of children. J Korean Soc Emerg Med 2012;23:537-542.

31. Kim JE, Ryoo SM, Kim YJ, et al. Incidence and clinical features of esophageal perforation caused by ingested foreign body. Korean J Gastroenterol 2015;66:255-260.

32. Sheth N, Diner WC. Swallowing problems in the elderly. Dysphagia 1988;2:209-215

33. Evans RM, Ahuja A, Rhys Williams S, Van Hasselt CA. The lateral neck radiograph in suspected impacted fish bones: does it have a role? Clin Radiol 1992;46:121-123.

34. Gautam V, Phillips J, Bowmer H, Reichl M. Foreign body in the throat. J Accid Emerg Med 1994;11:113-115.

35. Ginsberg GG. Management of ingested foreign objects and food bolus impactions. Gastrointest Endosc 1995;41:33-38.

36. Mosca S, Manes G, Martino R, et al. Endoscopic management of foreign bodies in the upper gastrointestinal tract: report on a series of 414 adult patients. Endoscopy 2001;33:692-696.

37. Sugawa C, Ono H, Taleb M, Lucas CE. Endoscopic management of foreign bodies in the upper gastrointestinal tract: a review. World J Gastrointest Endosc 2014;6:475-481.

38. Telford JJ. Management of ingested foreign bodies. Can J Gastroenterol 2005;19:599-601.

39. Connolly AA, Birchall M, Walsh-Waring GP, Moore-Gillon V. Ingested foreign bodies: patient-guided localization is a useful clinical tool. Clin Otolaryngol Allied Sci 1992;17:520-524.

40. Luk WH, Fan WC, Chan RY, Chan SW, Tse KH, Chan JC. Foreign body ingestion: comparison of diagnostic accuracy of computed tomography versus endoscopy. J Laryngol Otol 2009;123:535-540.

41. Ambe P, Weber SA, Schauer M, Knoefel WT. Swallowed foreign bodies in adults. Dtsch Arztebl Int 2012;109:869-875.

42. ASGE Standards of Practice Committee, Ikenberry SO, Jue TL, et al. Management of ingested foreign bodies and food impactions. Gastrointest Endosc 2011;73:1085-1091.

43. Ritchie T, Harvey M. The utility of plain radiography in assessment of upper aerodigestive tract fishbone impaction: an evaluation of $22 \mathrm{New}$ Zealand fish species. N Z Med J 2010;123:32-37.

44. Ngan JH, Fok PJ, Lai EC, Branicki FJ, Wong J. A prospective study on fish bone ingestion. Experience of 358 patients. Ann Surg 1990;211:459462.

45. Wu IS, Ho TL, Chang CC, Lee HS, Chen MK. Value of lateral neck 
radiography for ingested foreign bodies using the likelihood ratio. J Otolaryngol Head Neck Surg 2008;37:292-296.

46. Shihada R, Goldsher M, Sbait S, Luntz M. Three-dimensional computed tomography for detection and management of ingested foreign bodies. Ear Nose Throat J 2009;88:910-911.

47. Liew CJ, Poh AC, Tan TY. Finding nemo: imaging findings, pitfalls, and complications of ingested fish bones in the alimentary canal. Emerg Radiol 2013;20:311-322.

48. Marco De Lucas E, Sádaba P, Lastra García-Barón P, et al. Value of helical computed tomography in the management of upper esophageal foreign bodies. Acta Radiol 2004;45:369-374.

49. Goh BK, Tan YM, Lin SE, et al. CT in the preoperative diagnosis of fish bone perforation of the gastrointestinal tract. AJR Am J Roentgenol 2006;187:710-714.

50. Young CA, Menias CO, Bhalla S, Prasad SR. CT features of esophageal emergencies. Radiographics 2008;28:1541-1553.

51. Takada M, Kashiwagi R, Sakane M, Tabata F, Kuroda Y. 3D-CT diagnosis for ingested foreign bodies. Am J Emerg Med 2000;18:192-193.

52. Foley MJ, Ghahremani GG, Rogers LF. Reappraisal of contrast media used to detect upper gastrointestinal perforations: comparison of ionic water-soluble media with barium sulfate. Radiology 1982;144:231-237.

53. Loh KS, Tan LK, Smith JD, Yeoh KH, Dong F. Complications of foreign bodies in the esophagus. Otolaryngol Head Neck Surg 2000;123:613-616.

54. Chaikhouni A, Kratz JM, Crawford FA. Foreign bodies of the esophagus. Am Surg 1985;51:173-179.

55. Gmeiner D, von Rahden BH, Meco C, Hutter J, Oberascher G, Stein HJ. Flexible versus rigid endoscopy for treatment of foreign body impaction in the esophagus. Surg Endosc 2007;21:2026-2029.

56. Tan S, Tan S, Peng M, Yu F. Management of an ingested fish bone in the lung using video-assist thoracic surgery: a case report. Medicine (Baltimore) 2015;94:e943.

57. Li ZS, Sun ZX, Zou DW, Xu GM, Wu RP, Liao Z. Endoscopic management of foreign bodies in the upper-GI tract: experience with 1088 cases in China. Gastrointest Endosc 2006;64:485-492.

58. Zhang S, Wang J, Wang J, Zhong B, Chen M, Cui Y. Transparent cap-assisted endoscopic management of foreign bodies in the upper esophagus: a randomized, controlled trial. J Gastroenterol Hepatol 2013;28:1339-1342.

59. Lee JS, Chun HJ, Lee JM, et al. Salvage technique for endoscopic removal of a sharp fish bone impacted in the esophagus using a transparent cap and detachable snares. Korean J Gastroenterol 2013;61:215-218.

60. Singh B, Kantu M, Har-El G, Lucente FE. Complications associated with 327 foreign bodies of the pharynx, larynx, and esophagus. Ann Otol Rhinol Laryngol 1997;106:301-304.

61. Hokama A, Uechi K, Takeshima E, et al. A fish bone perforation of the esophagus. Endoscopy 2014;46 Suppl 1 UCTN:E216-E217.

62. Jeon SH, Han DC, Lee SG, Park HM, Shin DJ, Lee YB. Eikenella corrodens cervical spinal epidural abscess induced by a fish bone. J Korean Med Sci 2007;22:380-382.

63. Wei Y, Jahreiß L, Zhang Z, Albers AE. Acute airway obstruction due to retropharyngeal haematoma caused by a large fish bone in a patient with hypertension caused by a pheochromocytoma. BMJ Case Rep 2015;2015:bcr2014208644.

64. Sinha R, Sen I, Saha J, Mukherjee A, Guha R. Migration of a fish bone from the upper aerodigestive tract to the skin of the neck: a case report.
Ear Nose Throat J 2013;92:E15.

65. Aslan M, Çelik Y, Dülger AC, et al. Submucosal hematoma of the esophagus due to fish bone ingestion. Turk J Gastroenterol 2014;25 Suppl 1:302-303.

66. Kim HG, Kim BH, Lim DJ, Kang SH. A case of removal of esophageal foreign body causing esophageal submucosal hematoma. Korean J Otorhinolaryngol-Head Neck Surg 2007;50:958-960.

67. Wu HC, Hsia JY, Hsu CP. Esophageal laceration with intramural dissection mimics esophageal perforation. Interact Cardiovasc Thorac Surg 2008; 7:864-865.

68. Shim CS, Lee MS, Cho JY, et al. Esophagus, stomach \& intestine: a case of tracheoesophageal fistula caused by fish bone induced trauma with complete healing by using the fibrinogen: thrombin glue. Korean J Gastrointest Endosc 1997;17:49-54.

69. Mukhopadhyay B, Tripathy BB, Saha S, Shukla RM, Saha SR. Acquired tracheo-oesophageal fistula: a case report. J Indian Med Assoc 2008; 106:806, 808.

70. Pan S, Chai Y, Shen G. Recurrent pneumonia caused by a migrated esophageal foreign body. Thorac Cardiovasc Surg 2013;61:513-515.

71. Matsuda E, Okabe K, Takahagi A, et al. Pulmonary abscess caused by fish bone. Kyobu Geka 2013;66:219-222.

72. Kim YS, Lee SW, Kang SB, Nam SW, Lee DS, Park K. Esophageal perforation and empyema after fish bone swallowing. Korean J Gastrointest Endosc 2007;34:320-323.

73. Kim KM, Jang AS, Kim SW, et al. A case of acute mediastinitis associated with fish bone with successful conservative treatment. Tuberc Respir Dis 2002;53:344-348.

74. Choi EK, Kwon KH, Choi YW, Oh SK, Jeong JW, Park YK. A case of acute purulent pericarditis with pericardial performation by esophageal foreign body. J Korean Soc Echocardiogr 2000;8:247-251.

75. Liang H, Xu Z, Feng Q, Ma L. Recurrent cerebral embolism secondary to esophageal and atrial foreign body complicated by infective endocarditis. J Thorac Cardiovasc Surg 2014;148:e213-e214.

76. Blanco Ramos M, Rivo Vázquez JE, García-Fontán E, Amoedo TO. Systemic air embolism in a patient with ingestion of a foreign body. Interact Cardiovasc Thorac Surg 2009;8:292-294.

77. Kunishige H, Myojin K, Ishibashi Y, Ishii K, Kawasaki M, Oka J. Perforation of the esophagus by a fish bone leading to an infected pseudoaneurysm of the thoracic aorta. Gen Thorac Cardiovasc Surg 2008;56:427429.

78. Macchi V, Porzionato A, Bardini R, Parenti A, De Caro R. Rupture of ascending aorta secondary to esophageal perforation by fish bone. J Forensic Sci 2008;53:1181-1184.

79. Sauer BM, Staritz M, Perdekamp MG. Lethal bleeding after accidental swallowing of a wooden meat skewer. Z Gastroenterol 2009;47:749-752.

80. Valour F, Sénéchal A, Dupieux C, et al. Actinomycosis: etiology, clinical features, diagnosis, treatment, and management. Infect Drug Resist 2014;7:183-197.

81. Sung HY, Lee IS, Kim SI, et al. Clinical features of abdominal actinomycosis: a 15-year experience of a single institute. J Korean Med Sci 2011;26:932-937.

82. Kikuchi K, Tsurumaru D, Hiraka K, Komori M, Fujita N, Honda H. Unusual presentation of an esophageal foreign body granuloma caused by a fish bone: usefulness of multidetector computed tomography. Jpn J Radiol 2011;29:63-66. 